\title{
Corneal Crosslinking: The Standard Protocol
}

\author{
Cross-linking da cornea: protocolo padrão
}

Marcony R. Santhiago

\begin{abstract}
The purpose of this review is to determine the indications and efficacy of the surgery that promotes new covalent bonds between the collagen fibers of the cornea, known as Cross-Linking (CXL), as well as to clarify its objectives. Keratoconus is a bilateral, asymmetric ectasic disease of the cornea that mainly courses with steepening and progressive thinning, and usually begins in the second decade of life. The primary use of CXL has been in discontinuing the progression of keratoconus. Although known corneal stromal remodeling occurs in these patients, the pathophysiology behind keratoconus is still unknown and appears to be multifactorial. By the literary evidence available to date, the CXL of the cornea is safely indicated in patients with progressing disease. We conclude that there is sufficient evidence to affirm that cornea $C X L$ is effective in stabilizing corneal ectasic disease.

Keywords:Cornea/physiology; Cornea/metabolismo; Cross-linking reagents; Keratoconus/therapy; Riboflavin/administration \& dosage; Protocolos
\end{abstract}

\section{Resumo}

O objetivo desta revisão é de determinar as indicações e eficácia da cirurgia que promove novas ligações covalentes entre as fibras de colágeno da córnea, conhecida como Cross-Linking (CXL), assim como esclarecer seus objetivos. O ceratocone é uma doença ectasica da córnea, bilateral, assimétrica, que, principalmente, cursa com encurvamento e afinamentos progressivo, e se inicia em geral na segunda década de vida. O uso primário do CXL tem sido na interrupção da progressão do Ceratocone. Apesar do conhecido encurvamento no estroma da córnea ocorrer nesses pacientes, a fisiopatologia por trás do ceratocone ainda é desconhecida e parece ser multifatorial. Pela evidencia literária disponível até o momento, o CXL da córnea esta, portanto indicado nos pacientes com doença em progressão. Concluímos que existe evidencia suficiente para afirmar que o CXL da córnea é eficaz na estabilização da doença ectásica da cornea.

Descritores: Córnea/fisiologia; Córnea/metabolismo; Cross-linking reagentes; Ceratocone/terapia; Riblflavina/administração \& dosagem; Protocolos

Ophthalmology Department, Sao Paulo University, Sao Paulo, SP, Brazil.

Ophthalmology Department, Rio de Janeiro Federal University, Rio de Janeiro, RJ, Brazil.

The authors declare no conflicts of interests.

Receivedfor publication 25/11/2016 - Accepted for publication 18/01/2017 


\section{INTRODUCTION}

$\mathbf{0}$ bservation of lower keratoconus progressions in diabetic or elderly patients has led to the idea that natural crosslinking of the cornea's collagen fibers could result in tissue strengthening and hardening. ${ }^{(1)}$ This has led to the development of corneal reticulation or crosslinking (CXL), a process in which a combination of a photoinductor, ultra-violet light (UV), and a photochemical reaction induces free radicals, causing a chemical connection among collagen fibers.

An early study on animals revealed an increase of up to $70 \%$ in corneal rigidity ${ }^{(2)}$, while the first clinical study by Wollensak et al showed interrupted progression and smoothing of the corneal topography in keratoconus patients. ${ }^{\left({ }^{3}\right)}$ Since then, various prospective studies have echoed the same results in patients with keratoconus ${ }^{(4-6)}$ and corneal ectasia after refractive surgery (from now on referred to as "ectasia"). ${ }^{(7)}$

The objective of this review is to determine the indications of the surgery which promotes new covalent bonds among corneal collagen fibers, known as Cross-Linking (CXL), and to clarify its aims.

\section{Photoinductor}

Riboflavin functions as an excellent photoinductor in the CXL biochemical reaction. Even with a broad absorption range it is safe for systemic circulation. ${ }^{(8)}$ However, it is a relatively large molecule and its main limitation is adequate penetration into the corneal stroma through the complete epithelium, which is fundamental for its effective action. The standard (or traditional) technique to be discussed in this review includes removal of the epithelium. Several CXL techniques using the complete epithelium (called "epi on") have been studied to circumvent this problem, although the effectiveness of these protocols is controversial.

\section{Ultraviolet Light (UV)}

UV light is the second important component in CXL. Key parameters include wave length, fluency and irradiation time, which are specific for the treatment's effectiveness and safety. The peak range for riboflavin absorption in CXL varies between $360-370 \mathrm{~nm}$, as determined through initial studies. ${ }^{(9)}$ Variations in intensity and duration in pre-clinical studies established that the maximum rigidity involved the use of $3 \mathrm{~mW} /$ $\mathrm{cm}^{2}$ energy during 30 minutes, which corresponds to a total dose of energy (fluency) of $5.4 \mathrm{~J} / \mathrm{cm}^{2}$, and allowed greater tissue hardening efficiency. This form of use was called standard protocol (or Dresden protocol). Variations of this protocol, with greater fluency and less time, were called accelerated CXL and will be discussed in another chapter.

The photochemical reaction that leads to the real hardening process involves riboflavin absorbing the UV energy and the excitement of the molecule to creative reactive oxygen types. This reaction induces covalent bonds among the corneal collagen molecules themselves and between collagen and proteoglycans, ${ }^{(10)}$ a process that leads to greater biomechanical rigidity. Oxygen plays a fundamental role in this entire chemical reaction, although more studies are needed to fully understand this relationship and how the time and manner of exposure to oxygen may influence the treatment result.

\section{CXL application and indications}

\section{Keratoconus}

Keratoconus is an ectatic disease of the cornea. It is bilateral, asymmetric, mainly involves progressive curving and thinning, and generally begins in the second decade of life. ${ }^{(11)}$ Primary CXL use has been to interrupt keratoconus progression. Although the known curving of the corneal stroma occurs in these patients, the physiopathology behind keratoconus is still unknown and seems to be multifactorial.

According to the evidence in the available literature, discussed in more detail further ahead, corneal CXL is therefore indicated for patients with the disease in progression:

\section{Table 1}

\section{Main signs of progression}

- Increase of at least 1 diopter (D) in keratometric parameters in 12 months $(\mathrm{m})$

- Increase of at least $0.75 \mathrm{D}$ in keratometric parameters in $6 \mathrm{~m}$

- Myopia increase of $0.75 \mathrm{D}$ in $12 \mathrm{~m}$ in refraction under cyclopegia

- Loss of at least two lines of vision, in best corrected vision in $12 \mathrm{~m}$

Much has yet to be discussed about the way in which pachymetry, or pachymetric map, can be used to document progression and consequently indicate $\mathrm{CXL}$.

\section{Scientific evidence of treatment effectiveness}

The first clinical study involved patients with progressive keratoconus who were submitted to the standard (Dresden) protocol, which consisted in applying riboflavin on the cornea with its epithelium removed, prior to exposure during 30 minutes to a source of UV radiation with a luminous intensity of $3 \mathrm{~mW} /$ $\mathrm{cm} .^{(2,3)}$ The first controlled and randomized studies confirmed the effectiveness of safe interruption of the disease progression, including smoothing, improvement in visual acuity, transitory thinning of the cornea during the first six months and improvement in topographic parameters. ${ }^{(8,12)}$ Raiskup et al. ${ }^{(6)}$ published the study with the longest follow-up to date; ten years monitoring keratoconus patients, confirming stability, improvement of visual acuity and long-term topographic parameters. Studies conducted by our group have shown that CXL is also effective in keratoconus patients even when the disease is in advanced stages. ${ }^{(13)}$

In a recent systematic review with meta-analysis, awaiting publication, conducted by Santhiago and collaborators, consulting the MEDLINE, CINAHL, Cochrane Library and EMBASE databases and analyzing only comparative studies, it was shown that sufficient scientific evidence exists to assert that the standard CXL protocol is effective in interrupting the disease progression. Fifteen comparative studies were found, including eyes submitted to the standard CXL method and eyes not submitted to treatment, however, seven articles contain insufficient data for adequate analysis ${ }^{(14-20)}$ Our meta-analysis included, therefore, 396 eyes submitted to CXL, evaluated for a period ranging from 12 to 36 months, compared to 338 non-treated eyes. Other noncomparative studies corroborate the findings of interrupted progression and apparent safety of the treatment. ${ }^{(3-7,72,21-27)}$ 
Considering that keratoconus generally begins in the second decade of life and has a progressive nature, pediatric patients may benefit from treatment with CXL. ${ }^{(28)}$ Recent studies confirm the treatment's effectiveness, as well as the significant improvement of topographic features and visual acuity. ${ }^{29-30}$ However, further monitoring suggests that despite initial improvement, pediatric patients may present long-term progression. ${ }^{31}$ Additional studies are still needed and should focus on the development of appropriate techniques and protocol, not only to obtain lasting and effective results, but principally to ensure the safety of patients in pediatric age. Adequate advice to parents is essential in order for these to understand the disease's progressive nature and the necessity of intervention.

\section{We suggest CXL be indicated:}

- In cases of documented progressive keratoconus in the adult population

- When post-refractive surgery ectasia is diagnosed

-When keratoconus is diagnosed in the population aged under 18

Patients with 20/25 visual acuity or better, of any age, can choose for the disease to be merely monitored, as CXL also presents complications and may lead to reduced vision. Specifically in children, who still present adequate vision, the aim and potential complications of any surgical treatment must be discussed and clarified before any course of action is determined.

\section{Iatrogenic corneal ectasia}

Corneal ectasia after refractive surgery occurs due to biomechanical instability among collagen fibers, resulting in corneal thinning and curving similar to keratoconus. ${ }^{21}$ It is a progressive alteration by definition. ${ }^{(32-33)}$

Initial studies have shown that CXL is effective in interrupting ectatic progression ${ }^{7}$, and, subsequently, prospective studies revealed smoothing of the corneal topography and improvement in visual acuity a year after treatment. ${ }^{34}$ The specific risks for CXL in the treatment of post-LASIK ectasia include chance of haze, flap complications and epithelial growth on the interface.

\section{Evaluating treatment effectiveness}

The principal measure for identifying CXL results, that is, whether progression was interrupted, is longitudinal analysis of corneal curvature. Along with the keratoconus parameters $(\mathrm{K})$, such as maximum $\mathrm{K}$, central $\mathrm{K}$, more curved $\mathrm{K}$ and even smoother $\mathrm{K}$, the other variables that show progression and thus lead to treatment indication should also be used to monitor the result of stabilization, such as visual acuity and myopia. ${ }^{(12)}$

Clinically, a stromal demarcation line, which is probably one indication of treatment depth, can be detected with a slit lamp test although it is more easily verified through optical coherence tomography (OCT) of an earlier segment and/or confocal microscopy. ${ }^{(35)}$ The demarcation line probably represents the transition between a stroma that has been modified by CXL and a non-treated stroma, but it does not confirm the limit, or even the presence of a biomechanical reaction and it definitely does not necessarily represent the only alterations caused by CXL. The demarcation line appears not to be related to alteration in visual acuity or maximum keratometry. ${ }^{(36)}$

Laboratory studies provide objective data which confirm that CXL is in fact effective, through the visualization, with electronic microscopy, of the increase in collagen fiber diameter.
(37) Apart from greater resistance to enzymatic digestion, there is an increase in biomechanical rigidity, indicated by the increase in Young's modulus ${ }^{(2)}$ identified through imaging modalities such as atomic force microscopy ${ }^{(38)}$ and second-harmonic generation microscopy. Second-harmonic generation microscopy makes it possible to image collagen fibrils in high-contrast mode, generating tridimensional reconstruction and detecting differences in the lamellae of treated and non-treated corneas. ${ }^{(39)}$

The cornea has dynamic elastic properties and therefore topography supplies only a fraction of the information needed to determine the progression, regression or stability of the disease. The study of corneal biomechanics provides additional information that may lead to better determination of what postCXL effectiveness means.

\section{Monitoring and refractive measures}

After CXL for ectatic diseases of the cornea, we recommend monitoring the patient every 3 months in the 1st year and every 6 months from the 2 nd year. In general, measures with refractive purposes, such as contact lens adaptation after CXL, have better results after the most intense period of stromal remodeling, which lasts about 12 months. This has been the routine adopted by the author of this review.

\section{Safety parameters and potential complications}

Safety parameters focus on the protection of ocular structures, such as the corneal endothelium, lens and retina. Firstly, a corneal thickness of more than $400 \mu \mathrm{m}$ must be respected in order to protect the corneal endothelium. ${ }^{(40)}$ Once the epithelium has been removed, there is a risk of dehydration, which can cause significant thinning in some cases. Many patients with corneal ectasia, including keratoconus, present significant thinning before treatment.

Modified protocols use hypo-osmolar riboflavin, which promotes liquid retention, leading to an increase in thickness of up to about $25 \%$ of the original value and, in some cases, reaching the minimum recommended thickness. However, it is known that in corneas measuring less than $350 \mu \mathrm{m}$ it is unlikely that 400 $\mu \mathrm{m}$ can be reached. More recent studies have used dextran-free riboflavin to allow corneal thickness to increase. ${ }^{(41)}$ There is concern regarding the safety and effectiveness of these corneas with "iatrogenically modified" thicknesses, since response to CXL may be lower due to reduced concentration of collagen fibers in an artificially-hydrated cornea.

Another possible explanation for the risk of lower effectiveness is the fact that, after CXL, the cornea becomes more rigid mainly in the anterior $300 \mu \mathrm{m}$, thus an excessivelyhydrated cornea may be too deep for effective treatment. ${ }^{(42)}$

Another safety concern includes complications from the treatment itself. Removal of the epithelium creates a variety of risks: infiltrates, delayed re-epithelialization and infectious keratitis. When they occur, infiltrates are sterile and respond to corticoid treatment, probably representing the organism's own antibodies reacting to the modification of the corneal tissue. (43)

While it is being researched, the impact of corneal haze after CXL is still not understood. Keratocyte damage is also a concern, even in approaches which preserve the epithelium. However, studies have suggested that repopulation occurs within weeks or months after treatment. Other studies suggest that keratocyte apoptosis could be used as an indicator of CXL success. ${ }^{(44-45)}$ 


\section{Post-CXL remodeling and smoothing}

The remodeling and hardening associated to the post-CXL cicatricial process may lead to smoothing, often significant, thinning and even opacity. Many studies, including some conducted by our group, ${ }^{(46,47)}$ have shown that intense smoothing can occur after CXL, sometimes surpassing 10D. The best way to monitor this smoothing is through differential, comparative maps.

The main causes of intense smoothing are probably the localized increase of the tissue's elastic modulus, effective depth of treatment and the central location of the cone. ${ }^{(47,48)}$

Localized increase in the elastic modulus can be partly explained by a gradual visco-elastic adjustment to altered tissue stress distribution, imposed by a selective hardening of the cornea relative to the adjacent sclera. Theoretically, this hardening associated to CXL reduces the cornea's central tension and transfers it to the limbus, allowing for smoothing and hyperopia.

As a photochemical process, different biological barriers play a role in the treatment's effective depth. Within this context, different responses in relation to biomechanical properties or a greater or lower increase in the elastic modulus is probably explained by the disease's heterogeneity, which involves intrinsic interaction between collagen fibers and the cellular matrix and their orientations, which are specific for each patient. Thus, collagen fibers with more space between them, and more defective intertwining, allow for the CXL photochemical effect to reach deeper areas and provoke a more intense hardening of the cornea. This is probably the reason that more advanced (topographically, more curved corneas) are likely to be more smoothed.

The influence of central localization in greater smoothing is related to anchoring to the sclera at $360^{\circ}$, allowing a greater distribution of tensional forces and effect on curvature.

\section{Higher fluency CXL protocol (accelerated method)}

According to the Bunsen-Roscoe law of reciprocity, the same photochemical effect can be reached with a lower illumination time and corresponding higher irradiation intensity. Thus, 3 minutes of irradiation at $30 \mathrm{~mW} / \mathrm{cm}^{2}, 5$ minutes of irradiation at $18 \mathrm{~mW} / \mathrm{cm}^{2}$ or 10 minutes of irradiation at $9 \mathrm{~mW} /$ $\mathrm{cm}^{2}$ should obtain the same effect as 30 minutes of irradiation at $3 \mathrm{~mW} / \mathrm{cm}^{2}$, since all combinations of time and intensity result in the same energy quantity, $5.4 \mathrm{~J} / \mathrm{cm}^{2}$.

The luminous intensities described range from $7-30 \mathrm{~mW} /$ $\mathrm{cm}^{2}$, with an irradiation time of between 3 and 15 minutes and a pre-irradiation riboflavin exposure time of between 5 and 30 minutes. However, although there is not yet a standard protocol for the accelerated form, the results all reveal progression interruption, stability in keratometric values and, in some cases, even corneal smoothing. ${ }^{(49-54)}$

\section{New CXL indications}

Apart from the initial indications for stabilizing the ectatic disease process, new indications have recently been evaluated, including CXL combined with the excimer laser known as CXL plus ${ }^{(55)}$ and the PACK- CXL (known as photoactivated chromophore for keratitis), using CXL principles to treat corneal infections. ${ }^{(56)}$

\section{Plus}

The term CXL plus refers to the combination of CXL and excimer laser. Photorefractive keratectomy (PRK), guided by topography, allows the cornea to be remodeled, theoretically making it more regular, without tackling the disease's progressive nature. Studies have shown an improvement in visual acuity and stability with topo-guided PRK with CXL. ${ }^{(57)}$

The effectiveness and safety of this type of sequential treatment, the maximum depth of treatment and the use of mitomycin $\mathrm{C}$ are still being debated. If truly safe in the longterm, the association of topo-guided PRK and CXL may be promising for visual rehabilitation and interruption of disease progression.

Besides the documented potential complications such as opacity or thinning, there is still much to learn about, for example, which is the appropriate sequence, topographyguided PRK followed by CXL or the other way round. Or, whether they should follow one another immediately or there should be an interval before the second procedure. If guided PRK is performed first, and then CXL, the treatment could be highly unpredictable due to the remodeling processed associated to CXL, as discussed above. It is then better to perform CXL, wait approximately 12 months for remodeling and only then perform topography-guided surgery. We must remember that in this case an excimer laser would be employed on a theoretically-modified, hardened cornea, and the ablation rate would be different, as hypo-correction would occur. It is necessary to better understand the excimer laser's ablation rates after CXL.

We must also understand that when an excimer laser is used in corneas with keratoconus, the most studied and accepted option is topography-guided PRK. This is because, unlike other modalities of conventional or even wavefrontguided PRK, topography-guided PRK performs a combination of partial myopic PRK on the cone apex with hypermetric PRK in the adjacent area. This way there is less tissue removal from the thinnest and most affected area. It is also important to remember that the main function of this type of topographyguided treatment is not refractive correction and rather corneal regularization.

Wavefront-guided treatments do not seem more adequate than those guided by topography, firstly due to the difficulty of obtaining aberrometry tests that are reliable and can be reproduced in such irregular corneas, and secondly because in this type of treatment the software will identify the area with the most aberrations (generally the cone apex) and try to smooth it as much as possible, which can mean excessive thinning in an already diseased area.

\section{Photoactivated chromophore for keratitis - PACK-CXL}

In addition to ectasia treatment, the main CXL principles have been suggested as a treatment option for infectious keratitis, known as photoactivated chromophore for keratitis (PACKCXL). Theories include the capacity to directly damage the microorganism and increase resistance to enzymatic damage, prevent microbe replication, liberate free radicals and alter the ocular surface with the purpose of creating a hostile environment for microorganisms. 
In vivo studies on animals have shown effectiveness in treating pathogens in challenging keratitis, while clinical data show improvement in keratitis with concomitant use of antimicrobial agents. ${ }^{(57)}$ The only comparative prospective study that evaluates the use of medication alone versus medication associated to PACK-CXL was described by Said et al and revealed that the cure time was the same, with a trend for faster resolution in the PACK-CXL group. ${ }^{(58)} \mathrm{A}$ systematic review and meta-analysis of 12 case series suggests better cicatrization time in bacteria-related cases and worse prognosis and greater transplant risk in cases of fungi, acanthamoeba and gram-negative bacteria. ${ }^{(59)}$

Accelerated protocols also seem able to treat and eliminate pathogenic agents, allowing for quicker treatment and with equivalent resolution regarding pathogen death. Some case reports suggest that PACK-CXL alone may help in the treatment of infectious keratitis, but larger studies are needed.

Randomized prospective studies comparing treatment with medication, versus medication with PACK-CXL, versus PACK-CXL, would be ideal, but relevant ethical considerations exist. Nevertheless, PACK-CXL offers another treatment option for difficult cases of microbial keratitis.

To sum up, there is sufficient evidence to state that corneal CXL is effective in stabilizing ectatic corneal disease.

\section{ReFERENCES}

1. Daxer A, Misof K, Grabner B, Ettl A, Fratzl P. Collagen fibrils in the human corneal stroma: structure and aging. InvestOphthalmolVis Sci.1998;39(3):644-8.

2. Wollensak G, Spoerl E, Seiler T. Stress-strain measurements of human and porcine corneas after riboflavin-ultraviolet-A-induced cross-linking. J Cataract Refract Surg. 2003;29(9):1780-5.

3. Wollensak G, Spoerl E, Seiler T. Riboflavin/ultraviolet-a-induced collagen crosslinking for the treatment of keratoconus. Am J Ophthalmol. 2003;135(5):620-7.

4. Randleman JB, Khandelwal SS, Hafezi F. Corneal cross-linking. Surv Ophthalmol. 2015;60(6):509-23.

5. Vinciguerra P, Albe E, Trazza S, Rosetta P, Vinciguerra R, Seiler T, et al. Refractive, topographic, tomographic, and aberrometric analysis of keratoconic eyes undergoing corneal cross-linking. Ophthalmology. 2009;116(3):369-78.

6. Raiskup F, Theuring A, Pillunat LE, Spoerl E. Corneal collagen crosslinking with riboflavin and ultraviolet-A light in progressive keratoconus: Ten-year results. J Cataract Refract Surg. 2015;41(1):41-6.

7. Hafezi F, Kanellopoulos J, Wiltfang R, Seiler T. Corneal collagen crosslinking with riboflavin and ultraviolet $\mathrm{A}$ to treat induced keratectasia after laser in situ keratomileusis. J Cataract Refract Surg. 2007;33(12):2035-40.

8. Edwards AM. Structure and general properties of flavins. MethodsMol Biol.2014;1146:3-13.

9. Spoerl E, Mrochen M, Sliney D, Trokel S, Seiler T. Safety of UVAriboflavin cross-linking of the cornea. Cornea. 2007;26(4):385-9.

10. Zhang Y, Conrad AH, Conrad GW. Effects of ultraviolet-A and riboflavin on the interaction of collagen and proteoglycans during corneal cross-linking. J Biol Chem. 2011;286(15):13011-22.
11. Krachmer JH, Feder RS, Belin MW. Keratoconus and related noninflammatory corneal thinning disorders. Surv Ophthalmol. 1984;28(4):293-322.

12. Ghanem RC, Santhiago MR, Berti T, Netto MV, Ghanem VC. Topographic, corneal wavefront, and refractive outcomes 2 years after collagen crosslinking for progressive keratoconus. Cornea. 2014;33(1):43-8.

13. Giacomin NT, Netto MV, Torricelli AA, Marino GK, Bechara SJ, Espíndola RF, et al. Corneal collagen cross-linking in advanced keratoconus: a 4-year follow-up study. J Refract Surg. 2016;32(7):459-65.

14. Caporossi A, Mazzotta C, Baiocchi S, Caporossi T. Long-termresults of riboflavinultraviolet a cornealcollagencross-linking for keratoconus in Italy: the Sienaeyecrossstudy. Am J Ophthalmol. 2010;149(4):585-93.

15. Coskunseven E, Jankov MR 2nd, Hafezi F. Contralateral eye study of corneal collagen cross-linking with riboflavin and UVA irradiation in patients with keratoconus. J Refract Surg. 2009;25(4):371-6.

16. Hersh PS, Greenstein SA, Fry KL. Cornealcollagen crosslinking for keratoconus and cornealectasia: One-year results. J Cataract Refract Surg. 2011;37(1):149-60.

17. Henriquez MA, Izquierdo L Jr, Bernilla C, Zakrzewski PA, Mannis M. Riboflavin/Ultraviolet A cornealcollagencross-linking for the treatment of keratoconus: visualoutcomes and Scheimpfluganalysis. Cornea. 2011;30(3):281-6.

18. Wittig-Silva C, Chan E, Islam FM, Wu T, Whiting M, Snibson GR. A randomized, controlledtrial of cornealcollagencross-linking in progressivekeratoconus: three-year results. Ophthalmology. 2014;121(4):812-21.

19. Viswanathan D, Males J.Prospective longitudinal study of cornealcollagencross-linking in progressivekeratoconus. Clin Exp Ophthalmol. 2013;41(6):531-6.

20. Seyedian MA, Aliakbari S, Miraftab M, Hashemi H, Asgari S, Khabazkhoob M. Corneal Collagen Cross-Linking in the Treatment of Progressive Keratoconus: A Randomized Controlled Contralateral Eye Study. Middle East Afr J Ophthalmol. 2015;22(3):340-5.

21. Greenstein SA, Fry KL, Hersh PS. In vivobiomechanical changes after corneal collagencross-linking for keratoconus and cornealectasia: 1-yearanalysis of a randomized, controlled, clinicaltrial. Cornea. $2012 ; 31(1): 21-5$.

22. Greenstein SA, Fry KL, Hersh MJ, Hersh PS. Higher-order aberrations aftercornealcollagen crosslinking for keratoconus and cornealectasia. J Cataract Refract Surg. 2012;38(2):292-302.

23. Greenstein SA, Fry KL, Hersh PS. Corneal topography indices aftercornealcollagen crosslinking for keratoconus and cornealectasia: one-year results. J Cataract Refract Surg. 2011;37(7):1282-90.

24. Khattak A, Nakhli FR, Cheema HR. Cornealcollagencrosslinking for progressivekeratoconus in SaudiArabia: One-year controlled clinical trial analysis. Saudi J Ophthalmol. 2015 Oct;29(4):249-54.

25. Lamy R, Netto CF, Reis RG, Procopio B, Porco TC, Stewart JM, et al. Effects of cornealcross-linking on contrastsensitivity, visualacuity, and cornealtopography in patients with keratoconus. Cornea. 2013;32(5):591-6.

26. Lang SJ, Messmer EM, Geerling G, Mackert MJ, Brunner T, Dollak $\mathrm{S}$, et al. Prospective, randomized, double-blindtrial to investigate the efficacy and safety of cornealcross-linking to halt the progression of keratoconus. BMC Ophthalmol. 2015;15:78 
27. O'Brart DP, Chan E, Samaras K, Patel P, Shah SP. A randomised, prospectivestudy to investigate the efficacy of riboflavin/ultraviolet A (370nm) cornealcollagencross-linkage to halt the progression of keratoconus. Br J Ophthalmol. 2011;95(11):1519-24.

28. Leoni-Mesplie S, Mortemousque B, Touboul D, Malet F, Praud D, Mesplie N, et al. Scalability and severity of keratoconus in children. Am J Ophthalmol. 2012;154(1):56-62.

29. Uçakhan ÖÖ, Bayraktutar BN, Saglik A. Pediatric corneal collagen cross-linking: long-term follow-up of visual, refractive, and topographic outcomes. Cornea. 2016;35(2):162-8.

30. McAnena L, Doyle F, O'Keefe M. Cross-linking in children with keratoconus: a systematic review and meta-analysis. Acta Ophthalmol. 2016 Sep 28. doi: 10.1111/aos.13224.

31. Vinciguerra P, Albe E, Frueh BE, Trazza S, Epstein D. Two-year corneal cross-linking results in patients younger than 18 years with documented progressive keratoconus. Am J Ophthalmol. 2012;154(3):520-6.

32. Randleman JB, Woodward M, Lynn MJ, Stulting RD. Risk assessment for ectasia after corneal refractive surgery. Ophthalmology. 2008;115(1):37-50.

33. Santhiago MR, Smadja D, Gomes BF, Mello GR, Monteiro ML, Wilson SE, et al. Association between the percent tissue altered and post-laser in situ keratomileusis ectasia in eyes with normal preoperative topography. Am J Ophthalmol. 2014;158(1):87-95.

34. Richoz O, Mavrakanas N, Pajic B, Hafezi F. Corneal collagen cross-linking for ectasia after LASIK and photorefractive keratectomy: long-term results. Ophthalmology. 2013;120(7):1354-9.

35. Kymionis GD, Grentzelos MA, Plaka AD, Tsoulnaras KI, Diakonis VF, Liakopoulos DA, et al. Correlation of the corneal collagen cross-linking demarcation line using confocal microscopy and anterior segment optical coherence tomography in keratoconic patients. Am J Ophthalmol. 2014;157(1):110-5 e1.

36. Bouheraoua N, Jouve L, El Sanharawi M, Sandali O, Temstet C, Loriaut $\mathrm{P}$, et al. Optical coherence tomography and confocal microscopy following three different protocols of corneal collagencrosslinking in keratoconus. InvestOphthalmolVisSci. 2014;55(11):7601-9.

37. Wollensak G, Wilsch M, Spoerl E, Seiler T. Collagen fiber diameter in the rabbit cornea after collagen crosslinking by riboflavin/ UVA. Cornea. 2004;23(5):503-7.

38. Seifert J, Hammer CM, Rheinlaender J, Sel S, Scholz M, Paulsen F, et al. Distribution of Young's modulus in porcine corneas after riboflavin/UVA-induced collagen cross-linking as measured by atomic force microscopy. Plos One. 2014;9(1):e88186.

39. Tan HY, Chang YL, Lo W, Hsueh CM, Chen WL, Ghazaryan AA, et al. Characterizing the morphologic changes in collagen crosslinkedtreated corneas by Fourier transform-second harmonic generation imaging. J Cataract Refract Surg. 2013;39(5):779-88.

40. Kymionis GD, Portaliou DM, Diakonis VF, Kounis GA, Panagopoulou SI, Grentzelos MA. Corneal collagen cross-linking with riboflavin and ultraviolet-A irradiation in patients with thin corneas. Am J Ophthalmol. 2012;153(1):24-8.

41. Hafezi F, Mrochen M, Iseli HP, Seiler T. Collagen crosslinking with ultraviolet-A and hypoosmolar riboflavin solution in thin corneas. J Cataract Refract Surg. 2009;35(4):621-4.
42. Hafezi F. Limitation of collagen cross-linking with hypoosmolar riboflavin solution: failure in an extremely thin cornea. Cornea. 2011;30(8):917-9.

43. Ghanem RC, Netto MV, Ghanem VC, Santhiago MR, Wilson SE. Peripheral sterile corneal ring infiltrate after riboflavin-UVA collagen cross-linking in keratoconus. Cornea. 2012 ;31(6):702-5.

44. Greenstein SA, Fry KL, Bhatt J, Hersh PS. Natural history of corneal haze after collagen crosslinking for keratoconus and corneal ectasia: Scheimpflug and biomicroscopic analysis. J Cataract Refract Surg. 2010;36(12):2105-14.

45. Armstrong BK, Lin MP, Ford MR, Santhiago MR, Singh V, Grossman GH, et al. Biological and biomechanical responses to traditional epithelium-off and transepithelial riboflavin-UVA CXL techniques in rabbits. J RefractSurg. 2013;29(5):332-41.

46. Hafezi F, Koller T, Vinciguerra P, Seiler T. Marked remodeling of the anterior corneal surface following collagen cross-linking with riboflavin and UVA. Br J Ophthalmol. 2011;95:1171-2.

47. Santhiago MR, Giacomin NT, Medeiros CS, Smadja D, Bechara SJ. Intense early flattening after corneal collagen cross-linking. J Refract Surg. 201531(6):419-22.

48. Roy AS, Dupps WJ Jr. Patient-specific computational modeling of keratoconus progression and differential responses to collagen cross-linking. Invest Ophthalmol Vis Sci. 2011;52(12):9174-87.

49. Ozgurhan EB, Akcay BI, Kurt T, Yildirim Y, Demirok A. Accelerated corneal collagen cross-Linking in thin keratoconic corneas. J Refract Surg. 2015;31(6):386-390.

50. Shetty R, Pahuja NK, Nuijts RM, Ajani A, Jayadev C, Sharma C, et al. Current protocols of corneal collagen cross-linking: visual, refractive, and tomographic outcomes. Am J Ophthalmol. 2015;160(2):243-9.

51. Kymionis GD, Grentzelos MA, Kankariya VP, Liakopoulos DA, Portaliou DM, Tsoulnaras KI, et al. Safety of high-intensity corneal collagen crosslinking. J Cataract Refract Surg. 2014;40(8):1337-40.

52. Seiler T, Hafezi F. Corneal cross-linking-induced stromal demarcation line. Cornea. 2006; ;25(9):1057-9.

53. Touboul D, Efron N, Smadja D, Praud D, Malet F, Colin J. Corneal confocal microscopy following conventional, transepithelial, and accelerated corneal collagen cross-linking procedures for keratoconus. J Refract Surg. 2012; 28(11):769-76.

54. Kymionis GD, Tsoulnaras KI, Grentzelos MA, Plaka AD, Mikropoulos DG, Liakopoulos DA, et al. Corneal stroma demarcation line after standard and high-intensity collagen crosslinking determined with anterior segment optical coherence tomography. J Cataract Refract Surg. 2014; 40(5):736-40.

55. Kymionis GD, Grentzelos MA, Portaliou DM, Kankariya VP, Randleman JB. Corneal collagen cross-linking (CXL) combined with refractive procedures for the treatment of corneal ectatic disorders: CXL plus. J Refract Surg. 2014;30(8):566-76.

56. Hafezi F, Randleman JB. PACK-CXL: defining CXL for infectious keratitis. J Refract Surg. 2014;30(7):438-9.

57. Martins SA, Combs JC, Noguera G, Camacho W, Wittmann P, Walther R, et al. Antimicrobial efficacy of riboflavin/UVA combination $(365 \mathrm{~nm})$ in vitro for bacterial and fungal isolates: a potential new treatment for infectious keratitis. Invest ophthalmolVisSci. 2008;49(8):3402-8. 
58. Said DG, Elalfy MS, Gatzioufas Z, El-Zakzouk ES, Hassan MA, Saif MY, et al. Collagen cross-linking with photoactivated riboflavin (PACK-CXL) for the treatment of advanced infectious keratitis with corneal melting. Ophthalmology. 2014;121(7):1377-82.
59. Alio JL, Abbouda A, Valle DD, Del Castillo JM, Fernandez JA. Corneal cross linking and infectious keratitis: a systematic review with a meta-analysis of reported cases. J Ophthalmic Inflamm Infect. 2013;3(1):47. 